\title{
Remediation of 4-nonylphenol in aqueous solution by using free radicals generated by the oxidative reactions
}

\author{
Jamil Rima • Karine Assaker
}

Received: 8 October 2011 / Accepted: 30 November 2011 / Published online: 7 January 2012

(C) The Author(s) 2012. This article is published with open access at Springerlink.com

\begin{abstract}
Introduction This study relates to use of zerovalent iron to generate hydroxyl free radicals and undergo subsequent oxidation to destroy 4-nonylphenol (NP) by mild process in aqueous solution and activation of oxygen gas $\left(\mathrm{O}_{2}\right)$ at room temperature. This technology is based on a novel oxidative mechanism mediated by zerovalent iron rather than commonly used reduction mechanism.

Materials and methods A laboratory scale device consisting of a $250 \mathrm{ml}$ pyrex serum vials fixed to a Vortex agitator was used. Different amounts of zerovalent iron powder (ZVI; 1, 10 , and $30 \mathrm{~g} / \mathrm{l})$ at $\mathrm{pH} 4$ and room temperature with bubbling of oxygen gas were investigated.

Results and conclusion Experiments showed an observed degradation rate $k_{(\mathrm{obs})}$ directly proportional to the amount of iron. 4-Nonylphenol degradation reactions demonstrated first-order kinetics with a half-life of about $10.5 \pm 0.5$ and $3.5 \pm 0.2 \mathrm{~min}$ when experiments were conducted at $[\mathrm{ZVI}]=1$ and $30 \mathrm{~g} / 1$ respectively. Three analytical techniques were employed to monitor 4-nonylphenol degradation and mineralization: (1) spectrofluorimetry; (2) high-performance liquid chromatography; (3) total organic carbon meter (TOC meter). Results showed a complete disappearance of 4-nonylphenol after 20 min of contact with ZVI. The intermediate by-products of the reaction were not identified but the disappearance of NP was monitored by the three abovementioned techniques.
\end{abstract}

Responsible editor: Philippe Garrigues

J. Rima $(\bowtie) \cdot K$. Assaker

Department of Chemistry, Faculty of Sciences II,

Lebanese University,

Fanar, Lebanon

e-mail: jrima@ul.edu.lb
Keywords 4-Nonylphenol · Mineralization · Zerovalent iron - Oxidative reaction $\cdot$ Free radicals generation

\section{Introduction}

Alkylphenol ethoxylates (APEs) are one of the most widely used classes of surfactants. They have been used in domestic detergents, pesticide formulations and industrial products. APEs enter the environment primarily via industrial and municipal wastewater treatment plants (John et al. 2000; Ying et al. 2002). Studies have found out that APE metabolites are more toxic than the parent substances and possess the ability to mimic natural hormones by interacting with the estrogen receptors (Hill et al. 2002; Bechmann 1999 and Sumpter 1998).

4-Nonylphenol (NP) may persist in sediments for many months. For example, in a freshwater study, the dissipation half-life $\left(t_{1 / 2}\right)$ of NP in sediments was estimated at 66 days, and the time required for dissipation of $95 \%$ of NP was estimated at 401 days (Heinis et al. 1999).

Biodegradation is the most important process affecting the fate of NP and nonylphenol ethoxylate (NPEs; Ahel et al. 1994). NPEs undergo a two-stage degradation process. First, step removal of ethoxy groups results in the formation of intermediate biodegradation products (short-chain NPEs, nonylphenol ethoxycarboxylates, and NP (4-nonylphenol)). The second stage involves the ultimate conversion of those molecules to $\mathrm{CO}_{2}, \mathrm{H}_{2} \mathrm{O}$, and inorganic salts (Swisher 1987). In general, biodegradation takes a relatively long time, and may form intermediate products that can be highly toxic (Hill et al. 2002; Bechmann 1999; and Sumpter 1998). The intermediate degradation products are less readily biodegraded than the parent NPEs, and therefore ultimate biodegradation occurs more slowly (Ahel et al. 1994). Rates of 
biodegradation increase with increasing temperature (Ahel et al. 1994 and Manzano et al. 1999), and thus they are season-dependent.

Under anaerobic conditions, NPEs biodegrade into 4nonylphenol (4-NP) that is persistent, lipophilic, and tends to be more bio-accumulative than the parent compounds (Ahel and Giger 1993 and Ekelund et al. 1993). Sewage sludge applied to an agricultural land may contain NP, which can enter the food chain when it was discharged into waterways. NP is suspected to have hormone-mimicking properties and is suspected disruptor to the endocrine glands (Ekelund et al. 1990 and McLeese et al. 1981). It is very toxic at low concentrations and it was found at high concentrations in the environment (Kawasaki et al., 2001). Therefore, it is essential to develop a rapid and efficiently method of degradation or removal of this compound. Traditional ways used to remove NP and organic chemicals from contaminated water are based essentially on the ozonization (Kim et al. 2005; Wagner et al. 2002), photolysis (Mielcarek and Daczkowska 1999; Coly and Aaron 1998; Horikoshi and Hidaka 2002; Da Silva et al. 2002), biodegradation (Wang et al. 1998), reduction by iron powder (Bizzigotti et al. 1997; Ghauch et al. 1999; Rima 1998, Rima et al. 2005). Removal of NP from wastewater has been studied by encapsulation into cyclodextrin in order to minimize its release into the environment (Castillo et al., 2001; Bizzigotti et al. 1997). The solubility of 4-NP in hydroxypropyl-cyclodextrin (HP-CDs) solutions was investigated in order to evaluate it for soil remediation polluted by NP. Both ozone and activated carbon treatments have been used for removing NP. The degree of degradation increased with the increasing ozonization time. Weakly acidic compounds were produced from the 4-NP/HPCD inclusion complexes by ozonization. HP-CDs could be used for the removal of 4-NP from soil (Kawasaki et al. 2001).

The photodegradation of non-ionic surfactants (nonylphenol- and alcohol-polyethoxylates, $\mathrm{NPEO}_{x}$ and $\mathrm{C}_{n} \mathrm{EO}_{x}$ (mixture of non-ionic surfactants-AEOs, NPEO)) was investigated in different waters with and without a photoinducter (Fe(III); Castillo et al., 2001).

Gabriel et al. (2005) evaluated the effectiveness of three advanced oxidation techniques-peroxidase-mediated oxidation, sonication, and Fenton's reagent-mediated oxidation on the removal of 4-NP from water and wastewater. The effect of enzyme concentration, sonication time, $\mathrm{Fe}^{2+}: \mathrm{H}_{2} \mathrm{O}_{2}$ : $\mathrm{NP}$, solution $\mathrm{pH}$, ionic strength, and presence of a cocontaminant on NP removal were evaluated. Results indicate that advanced oxidation processes can result in effective $(>95 \%)$ removal of NP from water. These techniques can be used for water treatment or to "polish" the final effluent at municipal wastewater treatment facilities (Sweeney and Fische 1972).

Destruction of halogenated hydrocarbons (RX) by means of using zerovalent metals such as iron $\left(\mathrm{Fe}^{0}\right.$;
Sweeney and Fische 1972; Sweeney 1981; Senzaki and Kumagai 1988, 1989, 1991; Gillham 1993; Matheson and Tratnyek 1994; Rima 1998) is one of the technologies currently studied for either in situ or aboveground treatment of groundwater. $\mathrm{Fe}^{0}$ is a mild reductant that can reductively dehalogenate $\mathrm{RX}$ according to the Eqs 1a-1c. The reaction in the Eq. 1a is thermodynamically favorable (Vogel et al. 1987). (Aruoma 1993) Since the oxidation of $\mathrm{Fe}^{0}$ to $\mathrm{Fe}^{2+}$, Eq. $1 \mathrm{~b}$, is thermodynamically favorable (Weast 1984 and Gutteridge 1984), the reduction of $\mathrm{RX}$ by $\mathrm{Fe}^{0}$, Eq. 1c, should be favorable.

$\mathrm{RX}+\mathrm{H}^{+}+2 \mathrm{e}^{-} \rightarrow \mathrm{RH}+\mathrm{X}^{-}$

$\mathrm{Fe}^{0} \rightarrow \mathrm{Fe}^{2+}+2 \mathrm{e}^{-}$

$\mathrm{Fe}^{0}+\mathrm{RX}+\mathrm{H}^{+} \rightarrow \mathrm{Fe}^{2+}+\mathrm{RH}+\mathrm{X}^{-}$

In this paper, free radicals were generated according the following mechanisms

$$
\begin{gathered}
\mathrm{O}_{2-}+\mathrm{H}^{+} \rightarrow \mathrm{HO}_{2}^{\bullet} \\
\frac{\mathrm{HO}_{2}+\mathrm{O}_{2}{ }^{-}+\mathrm{H}^{+} \rightarrow \mathrm{H}_{2} \mathrm{O}_{2}+\mathrm{O}_{2}}{\text { overall } \mathrm{O}_{2}-+\mathrm{O}_{2}-+2 \mathrm{H}^{+} \rightarrow \mathrm{H}_{2} \mathrm{O}_{2}+\mathrm{O}_{2}}
\end{gathered}
$$

Hydroxyl radicals $\left({ }^{\circ} \mathrm{OH}\right)$ can be produced according to the following reaction:

$\mathrm{H}_{2} \mathrm{O}_{2}+\mathrm{Fe}^{2+} \rightarrow \mathrm{OH}^{-}+\bullet{ }^{\bullet} \mathrm{OH}+\mathrm{Fe}^{3+}$

The hydroxyl free radical is an extremely reactive oxidizing agent that will react with most molecules at diffusion controlled rates, which means that reactions will occur immediately.

However, no report concerning the treatment of organics or more specifically 4-nonylphenol by free radicals generated by zerovalent iron.

The objective of this work is to remediate water contaminated by toxic organic compounds such as 4-Nonylphenol by mineralization using rapid and efficient new technology based on the generation of free radicals by oxidative reactions.

\section{Experimental section}

\subsection{Chemicals and reagents}

All reagents were of analytical grade. 4-Nonylphenol, 2deoxy-D-ribose (D), glacial acetic acid, sodium acetate trihydrate, and sodium hydroxide were purchased from Sigma Chemical Co. (St. Louis, MO, USA). 2-Thiobarbituric acid 
(TBA) was purchased from Fluka AG (Buchs, Switzerland), and zerovalent iron powder (ZVIP; 325 mesh) was from Merck (Darmstadt, Germany). ZVIP was washed by $\mathrm{HCl}$ $0.1 \mathrm{M}$ to remove impurities from the surfaces of particles Double-distilled water was deionized with Milli-Q water purification system (Millipore) and filtered by a Millipak 40 cartridge $(0.22 \mu \mathrm{m})$ before use.

\section{Equipment}

\subsection{High-performance liquid chromatography}

The degradation of NP was monitored on a highperformance liquid chromatography (HPLC) liquid chromatography using a Hewlett-Packard system (HP1100) equipped with a mono-channel UV-Visible detector and an automatic injector. The experiments were performed by UV detector at $260 \mathrm{~nm}$ by using a reverse phase Merck column (Spherisorb ODS $25 \mu \mathrm{m} ; 250$ $4.6 \mathrm{~mm})$. The flow rate was $1 \mathrm{ml} \mathrm{m^{-1 }}$ and the injected volume was $50 \mu \mathrm{l}$. The elution was accomplished with water $(\mathrm{pH}=6$ using phosphate buffer) and acetonitrile $(9.5 / 0.5 v / v)$.

\subsection{Analysis of total organic carbon}

Total organic carbon (TOC) contents were measured with a Shimadzu TOC Analyzer model 5050A (Japan). Water was used as blank controls. TOC was measured before and after reaction. TOC contents of the samples were determined with catalytic oxidation at $850^{\circ} \mathrm{C}$ in presence of $\mathrm{O}_{2}$ and $\mathrm{CeO}_{2}$ followed by acidification with $10 \% \mathrm{H}_{3} \mathrm{PO}_{4}$. The TOC Analyzer converts organic carbon to carbon dioxide by combustion. The carbon dioxide is then detected by the non-dispersive infrared gas analyzer (NDIR). The NDIR generates a detection signal which is converted to a peak, whose area is calculated by a data processor.

An aliquot of $250 \mathrm{~mL}$ of $\mathrm{NP}$ solution $(6 \mathrm{mg} / \mathrm{L})$ at $\mathrm{pH} 4$ was mixed with $2.5 \mathrm{~g}$ ZVIP. Oxygen gas was bubbling into the mixture during the course of reaction. By a 3-min interval, $3 \mathrm{~mL}$ of the solution was taken for HPLC, spectrofluorimeteric, and for TOC determination. The time of the reaction was about $20 \mathrm{~min}$.

\subsection{Spectrophotometry and spectrofluorimetry}

UV-Visible spectra were recorded on a Shimadzu UV1601 spectrophotometer (Japan). Fluorescence spectra were recorded on a Shimadzu spectrofluorimeter RF-5301 PC series (Japan) equipped with a 150-W xenon lamp. The $\mathrm{pH}$ was measured with a Mettler Toledo $\mathrm{pH}$-meter.

\subsection{Sample preparation}

Batches of tests were conducted in $50 \mathrm{~mL}$ of NP aqueous solution adjusted to $\mathrm{pH} 4$ by using $0.1 \mathrm{M} \mathrm{HCl}$, and then transferred into glass vials. Each sample contains $0.5 \mathrm{~g}$ of ZVIP, while it was bubbled with oxygen gas. Samples of $3 \mathrm{~mL}$ were withdrawn at $0,3,6,9,15,20$ and $35 \mathrm{~min}$. A volume of $0.5 \mathrm{~mL}$ of $1 \mathrm{M} \mathrm{NaOH}$ solution was added to the $3 \mathrm{~mL}$ withdrawn from the batches in order to remove the cationic iron $\mathrm{Fe}^{2+}$ or $\mathrm{Fe}^{3+}$ produced during the reaction in the purpose to avoid fluorescence quenching by the cationic iron as heavy external atoms. The same samples were monitored by HPLC to confirm the degradation of NP.

\subsection{Degradation of 4-NP by using ZVIP (zerovalent iron} powder)

A NP solution was placed in a batch reactor consisted of a 250-ml Erlenmeyer flask sealed with parafilm to reduce evaporation losses. The solution was adjusted to $\mathrm{pH} 4$ followed by addition of ZVIP $(1 ; 10$ or $30 \mathrm{~g} / 1)$. Oxygen gas was bubbled into the mixture. Aliquots of the solution $(3 \mathrm{~mL})$ were withdrawn each $3 \mathrm{~min}$ for analysis.

3.6 Detection of free radicals or demonstration of free radicals generation from $\mathrm{ZVI}$

Deoxyribose stock solution was prepared at $200 \mathrm{mg} / \mathrm{L}$ $(1.5 \mathrm{mM})$. The final concentrations of deoxyribose $(0.6 \mathrm{mM})$ were prepared by performing appropriate dilution. The ZVI was added to the vial containing $100 \mathrm{~mL}$ of deoxyribose solution followed by adjusting $\mathrm{pH}$ to 4 . The vial was sealed with a butyl rubber stopper, and shaken continuously for the duration of the experiment $(3 \mathrm{~min})$. For the analysis, an aliquot of $3 \mathrm{~mL}$ of the sample solution was added to $3 \mathrm{~mL}$ of TBA in $15 \%$ acetic acid $(1 \%$ of TBA, $w / v)$. The mixture was heated in a water bath maintained at $100^{\circ} \mathrm{C}$ for $15 \mathrm{~min}$. After the mixture was cooled, the absorption spectrum of the mixture was measured.

\section{Results and discussion}

\subsection{Degradation of 4-NP by ZVIP}

The mixture of NP aqueous solution with a concentration of $6 \mathrm{pp}$ at $\mathrm{pH}=4$ in the presence of $10 \mathrm{~g} / \mathrm{L}$ of $\mathrm{ZVIP}$, was shaken 
while oxygen gas was bubbled into the solution during the reaction time. At an interval of $3 \mathrm{~min}, 3 \mathrm{~mL}$ of the solution was withdrawn for analysis. Figure 1 shows the fluorescence evolution of the samples over the reaction period. These spectra were obtained by excitation and emission wavelengths at 260 and $305 \mathrm{~nm}$, respectively. After 20 min of the treatment, NP disappeared completely. HPLC monitoring was also carried out in parallel to the fluorescence measurements.

HPLC was used to monitor the evolution of NP by observing the chromatograms obtained during the reaction. It was shown that the 4-nonylphenol appeared at retention time $\mathrm{Rt}=12 \mathrm{~min}$. After $6 \mathrm{~min}$ of reaction, results show a decrease of $60 \%$ of 4 -nonylphenol concentration. At $20 \mathrm{~min}$ of reaction, the NP become undetectable.

For any particular amount of iron, NP degradation under oxidation conditions exhibits pseudo first-order decay with a linear dependence of $\operatorname{Ln}\left[C_{0} / C\right]$ on time. Figure 2 shows a linear dependence of rate of NP degradation on the amount of iron is observed.

As can be seen in this figure the NP disappearance rate is strongly dependent on the amount of iron which affects the degradation rate observed $\left(k_{\text {obs }}\right)$ of NP, presumably because the reactive $\mathrm{Fe}^{0}$ site concentration increases proportionally with $\mathrm{Fe}^{0}$ concentration. The linear regression of $k_{\mathrm{obs}}$ versus $\mathrm{Fe}^{0}$ content was $k_{\mathrm{obs}}=0 / 004\left[\mathrm{Fe}^{0}\right.$ content $\left.(\mathrm{g} / \mathrm{l})\right]+0.0076$

Table 1 summarizes the results obtained for the degradation rates in function of the mass of iron. Half- life time of NP decreases from 10.5 to $3.5 \mathrm{~min}$ by increasing the amount of iron from 1 to $30 \mathrm{~g} / \mathrm{l}$.

\subsection{Effect of the presence of oxygen}

The degradation of NP was examined both under deoxygenated by purging nitrogen in the reactor and in the presence of

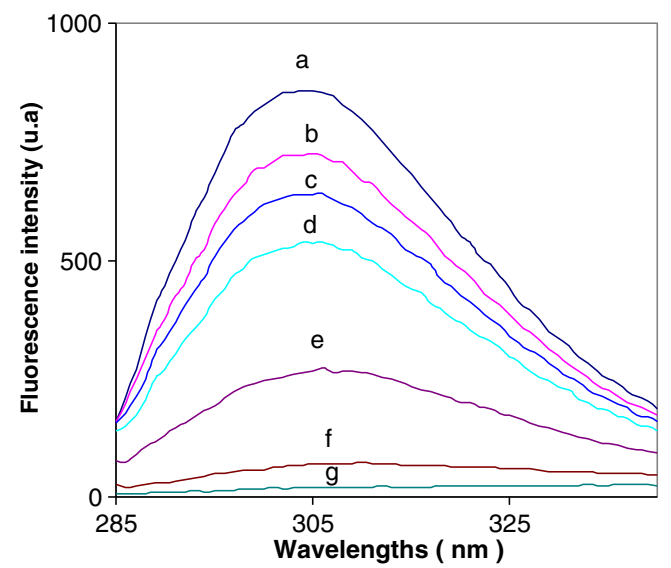

Fig. 1 Evolution of 4-nonylphenol fluorescence spectra with the time of reaction during the contact with zerovalent iron powder $10 \mathrm{~g} / \mathrm{L}, \mathrm{pH}=$ 4 , with oxygen. Times of the reactions are: $0,3,6,9,12,15,20 \mathrm{~min}$, respectively, from top to bottom $(\mathbf{a}, \mathbf{b}, \mathbf{c}, \mathbf{d}, \mathbf{e}, \mathbf{f}, \mathbf{g})$

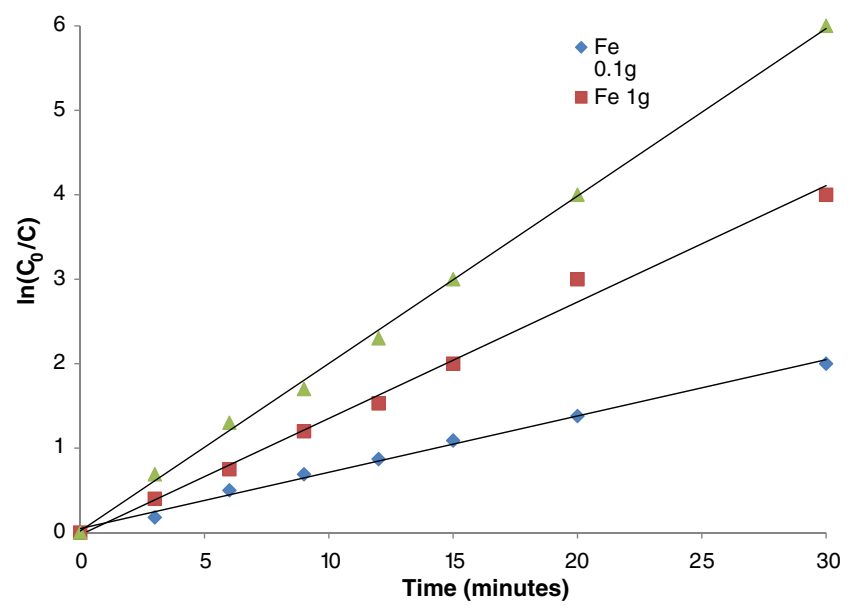

Fig. 2 Effect of the amount of iron on the NP degradation rate using 1, 10 , and $-30 \mathrm{~g} / \mathrm{l}$ of zerovalent iron powder ( $325 \mathrm{mesh}$ ) in aqueous NP solutions $[6 \mathrm{ppm}]$ at $\mathrm{pH}=4$

air or $100 \%$ oxygen. Experimental data show little removal of $\mathrm{NP}$ in $\mathrm{pH}=4$ solutions in the absence of oxygen while $71 \%$ removal was observed over 6 min when sample was bubbled with air or oxygen and when the amount of iron is $30 \mathrm{~g} / \mathrm{l}$. Removal was further enhanced when the suspension was bubbled with pure oxygen.

The presence of oxygen in the degradation process lead to the hydroxyl free radicals according to our hypothesis proposed in the introduction

$\mathrm{Fe}^{0}+\mathrm{O}_{2(\mathrm{aq})}+2 \mathrm{H}^{+} \rightarrow \mathrm{Fe}^{2+}+\mathrm{H}_{2} \mathrm{O}_{2} \rightarrow \mathrm{Fe}^{3+}+\bullet \mathrm{OH}+\mathrm{OH}^{-}$ Free radicals + Organics $\rightarrow$ Mineralization

However, under nitrogen gas, the oxidative reaction cannot be observed due to the unfavorable free radicals formation.

\subsection{Detection of free radicals}

The reaction of deoxyribose and hydroxyl free radical has been discussed extensively in the literature (Aruoma 1993; Gutteridge 1984; Halliwell and Gutteridge 1981; Halliwell 1978; Kosugi et al. 1987) Hydroxyl radicals attack deoxyribose to form products that react with TBA upon heating at low $\mathrm{pH}$ and yield a pink chromogen. Figure 3 presents the proposal mechanism of chromogen formation from reaction

Table 1 Kinetics of NP degradation (6 ppm) in function of the mass of iron powder

\begin{tabular}{lccc}
\hline Mass of iron $(\mathrm{g})$ & Linear equation & $k_{\mathrm{obs}}\left(\mathrm{min}^{-1}\right)$ & $R^{2}$ \\
\hline 0.1 & $y=0.066 x+0.047$ & 0.066 & 0.994 \\
1 & $y=0.137 x-0.026$ & 0.137 & 0.992 \\
3 & $y=0.198 x+0.018$ & 0.198 & 0.998 \\
\hline
\end{tabular}




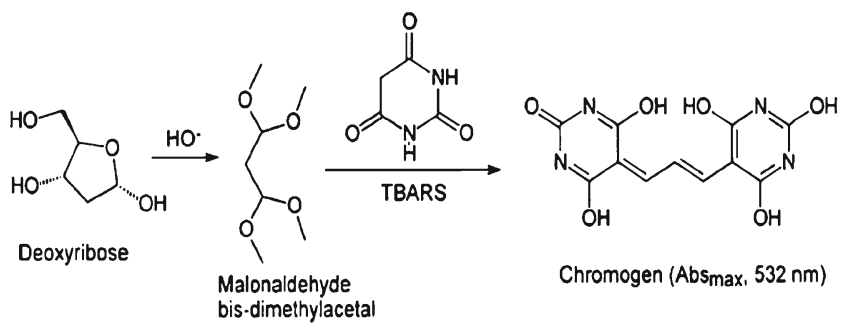

Fig. 3 Proposed mechanism of chromogen formation from reaction of deoxyribose and hydroxyl free radicals generated from zerovalent iron followed by reaction with thiobarbituric acid (TBA; thiobarbiturate reactive substances (TBARS) are the low molecular weight end products, whose main component is malondialdehyde, that are formed during the reaction)

of deoxyribose and hydroxyl free radicals generated from zerovalent powder followed by reaction with TBA. Thiobarbituric reactive substances are the low molecular weight end products, whose main component is malondialdehyde that are formed during the reaction.

Figure 4 shows the absorption spectrum of chromogen formed, which is identical to the spectrum of malonaldehyde bis-dimethylacetal (MDA)-TBA adduct (i.e., chromogen) obtained by Kosugi et al. (1987). There is one possibility to transform deoxyribose to MDA, which must be derived from a reaction between deoxyribose and hydroxyl free radicals. Hydroxyl free radicals are generated from ZVIP in aqueous buffer solution at an acidic condition (e.g., $\mathrm{pH} 4$ ).

In this section, we demonstrated that when zerovalent iron powder was mixed in aqueous solutions at $\mathrm{pH}$ less than 6 and under oxygen gas, the free radicals can be generated and indirectly observed by its reaction with TBA and chromogen formation as previously described.

The free radicals generated according to the mentioned conditions (acidic $\mathrm{pH}$, presence of oxygen gas and the use of zerovalent iron powder) should be able to mineralize the organic present in the aqueous solution such as NP.

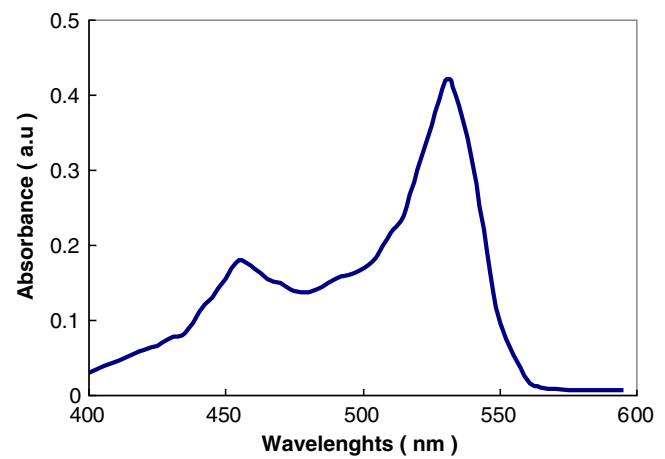

Fig. 4 Absorption spectrum of chromogen $\left(\lambda_{\max }\right.$ at $\left.532 \mathrm{~nm}\right)$. An aliquot of $3 \mathrm{~mL}$ of TBA was added into an equal volume reaction mixture of iron and deoxyribose in a solution $\mathrm{pH}=4$, and then was heated at $100^{\circ} \mathrm{C}$ for $15 \mathrm{~min}$

\subsection{Total organic compounds measurement}

In the TOC test, the production of carbon dioxide is measured upon complete oxidation of organic material through combustion at high temperature. The carbon dioxide mass is indicative of the mass of organic carbon initially present in the sample and the $\mathrm{CO}_{2}$ released during the oxidization of organic carbon determining the total organic carbon level Total organic carbon were measured in NP solutions in order to follow the disappearance of the NP while the carbon dioxide is then detected by the NDIR to show the conversion of NP into carbon dioxide or to show the fate of the NP at the end of the reaction.

Figure 5 shows plots of NP dissipation and carbon dioxide emitted over the course of reaction. The results show the production of carbon dioxide as decreasing TOC and the rate of the NP degradation, which indicates that after $20 \mathrm{~min}$, more than $98 \%$ of NP disappeared.

\section{Conclusion}

We demonstrated that ZVI generates free radicals in aqueous solution at acidic $\mathrm{pH}$ and in the presence of oxygen. Organic chemicals such as NP can be mineralized by the free radicals with a relatively short period of time. 4Nonylphenol degradation reactions demonstrated firstorder kinetics with a half-life of about $10.5 \pm 0.5$ and $3.5 \pm$ $0.2 \mathrm{~min}$ when experiments were conducted at $[\mathrm{ZVI}]=1$ and $30 \mathrm{~g} / \mathrm{l}$ respectively. This process provides different advantages by increasing the rate of the reaction by the environmentally friendly way of treatment converting the toxic compounds into carbon dioxide and water. The process is also economic compared to the traditional technologies of treatment.

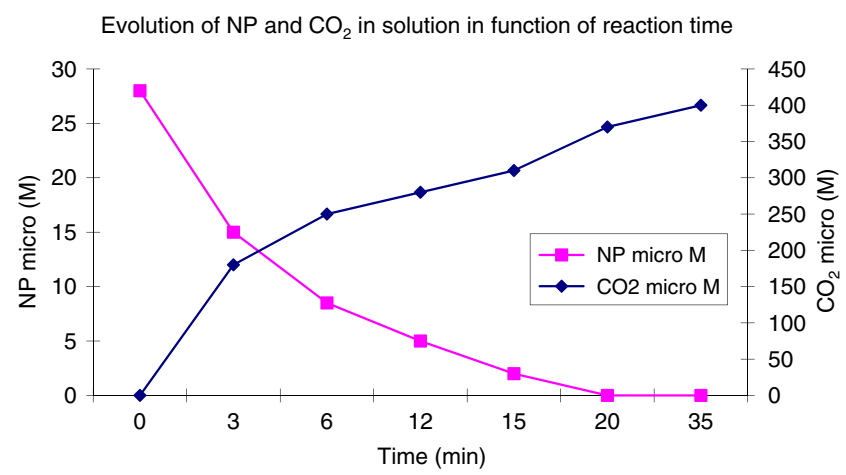

Fig. 5 4-Nonylphenol degradation and carbon dioxide formation: On the $Y$ axis, we plot the decreasing of NP at the left side. At right side, we plotted the increasing of carbon dioxide. In the $X$ axis, we present the time in minutes 
Open Access This article is distributed under the terms of the Creative Commons Attribution Noncommercial License which permits any noncommercial use, distribution, and reproduction in any medium, provided the original author(s) and source are credited.

\section{References}

Ahel M, Giger W (1993) Aqueous solubility of alkylphenols and alkylphenol ethoxylates. Chemo 26:1461-1470

Ahel M, Giger W, Schaffner C (1994) Behaviour of alkylphenol polyethoxylate surfactants in the aquatic environment: 2 . Occurrence and transformation in rivers. Water Res 28:1143-1152

Aruoma OI (1993) In: Aruoma OI (ed) Free radicals in tropical diseases. Harwood, London, Chapter 11

Bechmann RK (1999) Effect of the endocrine disrupter nonylphenol on the marine copepod Tisbe battagliai. Sci Total Environ 233:33-46

Bizzigotti GO, Reynolds DA, Kupper BH (1997) Enhanced solubilization and destruction of tetrachloroethylene by hydroxypropyl$\beta$ - cyclodextrin and iron. Environ Sci Technol 31:472-478

Castillo M, Penuela G, Barcelo D (2001) Identification of photocatalytic degradation products of non-ionic polyethoxylated surfactants in wastewaters by solid-phase extraction followed by liquid chromatography-mass spectro. Fresenius J Anal Chem 369:620-628

Coly A, Aaron J-J (1998) Cyclodextrin-enhanced fluorescence and photochemically-induced fluorescence determination of five aromatic pesticides in water. Anal Chimica Acta 380:129-141

Da Silva JP, Vieira Ferreira LF, Da Silva AM, Oliveira AS (2002) A comparative study of the photophysics and photochemistry of 4chlorophenol adsorbed on silicalite and $\beta$-cyclodextrin. J Photochem Photobio A, Chem 151:157-164

Ekelund R, Bergman Å, Granmo Å, Berggren M (1990) Bioaccumulation of 4-nonylphenol in marine animals a re-evaluation. Environ Pollut 64:107-120

Ekelund R, Granmo Å, Magnusson K, Berggren M, Bergman $\AA$ (1993) Biodegradation of 4-nonylphenol in seawater and sediment. Environ Pollut 79:59-61

Gabriel FLP, Giger W, Guenther K, Kohler H-P E (2005) Differential degradation of nonylphenol isomers by Sphingomonas xenophaga Bayram. Appl Environ Microbiol 71:1123-1129

Ghauch A, Rima J, Amine C, Martin-Bouyer M (1999) Rapid treatment of water and parathion with zero-valent iron. Chemo 39:1309-1315

Gillham RW (1993) Cleaning halogenated contaminants from groundwater. U.S patent N0 5,266,213.

Gutteridge JMC (1984) Reactivity of hydroxyl and hydroxyl-like radical discriminated by release of thiobarbituric-acid-reactive material from deoxyribose, nucleosides and benzoate. Biochem $\mathrm{J}$ 243:803-808

Halliwell B (1978) Superoxide-dependent formation of hydroxyl radicals in the presence of iron salts. FEBS Lett 96:238-242

Halliwell B, Gutteridge JMC (1981) Formation of a thiobarbituric-acidreactive substance from deoxyribose in the presence of iron salts. The role of superoxide and hydroxyl radicals. FEBS Lett 128:347-352

Heinis LJ, Knuth ML, Liber K, Sheedy BR, Tunell RL, Ankley GT (1999) Persistence and distribution of 4-nonylphenol following repeated application to littoral enclosures. Environ Toxicol Chem 18:363-375

Hill M, Stabile C, Steffen LK, Hill A (2002) Toxic effects of endocrine disrupters on freshwater sponges: common developmental abnormalities. Environ Pollut 117:295-300

Horikoshi S, Hidaka H (2002) Photodegradation mechanism of heterocyclic two. J Photochemi Photobio A, Chem 153:33-40
John DM, House WA, White GF (2000) Environmental fate of nonylphenol thoxylates: differential adsorption of homologs to components of river sediment. Environ Toxicol Chem 19:293-300

Kawasaki N, Araki M, Tanada S (2001) Inclusion behavior of 4nonylphenol into cyclodextrins derivatives. J Colloid Interface Sci 238:215-218

Kim J, Korshin GV, Velichenko AB (2005) Comparative study of electrochemical degradation and ozonation of nonylphenol. Water Res 39:2527-2534

Kosugi H, Kato T, Kikugawa K (1987) Formation of yellow, orange, and red pigments in the reaction of alk-2-enals with 2thiobarbituric acid. Anal Biochem 165:456-464

Manzano MA, Perales JA, Sales D, Quiroga JM (1999) The effect of temperature on the biodegradation of a nonylphenol polyethoxylate in river water. Water Res 33:2593-2600

Matheson LJ, Tratnyek PG (1994) Reductive dehalogenation of chlorinated methanes by iron metal. Environ Sci Technol 28:20452053

McLeese DW, Zitko V, Sergeant DB, Burridge L, Metcalfe CD (1981) Lethality and accumulation of alkylphenols in aquatic fauna. Chemo 10:723-730

Mielcarek J, Daczkowska E (1999) Photodegradation of inclusion complexes of isradipine with methyl- $\beta$-cyclodextrin. J Pharmac Biomed Analysis 21:393-398

Rima J (1998) Rapid degradation of parathion and atrazine using zerovalent. Poster symposium, Vancouver

Rima J, Aoun E, Hanna K, Li QX (2005) Degradation of phenol, into mineral compounds, in aqueous solutions using zero-valent iron powder (ZVIP). J Phys IV France 124:81-89

Senzaki T, Kumagai Y (1988) Removal of chlorinated organic compounds from wastewater by reduction process: treatment of 1,1,2,2-tetrachloroethane with iron powder. Kogyo Yosui 357:2-7

Senzaki T, Kumagai Y (1989) Removal of chlorinated organic compounds from wastewater by reduction process: treatment of trichloroethylene with iron powder. Kogyo Yosui 369:19-25

Senzaki T, Kumagai Y (1991) Removal of chlorinated organic compounds from wastewater by reduction process: treatment of trichloroethylene with iron powder. Kogyo Yosui 391:29-35

Sumpter JP (1998) Xenoendocrine disrupters - environmental impacts. Toxicol Lett 102:337-342

Sweeney K-I (1981) The reductive of industrial wastewater: Process description In: Bennett GF (Ed.), American institute of Chemical Engineers, Symposium Series, Water -1980, 77(209):67-71

Sweeney K, Fische JR (1972) Reductive degradation of halogenated pesticides. U.S patent No 3,640,821

Swisher RD (1987) Surfactant biodegradation, 2nd ed.; Surfactant. Science Series 18; Marcel Dekker: New York, 1987; p. 1085

Vogel TM, Gridlle CS, McCarty PL (1987) Transformations of halogenated aliphatic compounds. Environ Sci Technol 21:722-736

Wagner J, Bhandari A, Singh H, MacRitchie F (2002) Proceedings water research technology. An evaluation of advanced oxidation processes for the removal of 4-nonylphenol from water and wastewater. The 2002 Conference: the Application of Waste Remediation Technologies to Agricultural Contamination of Water Resources was organized by the Great Plains/Rocky Mountain (HSRC), Kansas City, MO, USA

Wang J-M, Marlowe EM, Miller-Maier RM, Brusseau ML (1998) Cyclodextrin-enhanced biodegradation of phenanthrene. Environ Sci Technol 32:1907-1912

Weast RC (1984) Light yellow prisms from alcohol. In: CRC Handbook of Chemistry and Physics, 64th Ed., CRC, Boca Raton, Florida, USA

Ying GG, Williams B, Kookana R (2002) Environmental fate of alkylphenols and alkylphenol ethoxylates - a review. Environ Int 28:215-226 